\title{
Molecular discrimination of pouched four-eyed opossums from the Mamirauá Reserve in the Brazilian Amazon
}

\author{
Cláudia Nunes ${ }^{1}$, Jose Marcio Ayres ${ }^{\dagger}$, Iracilda Sampaio ${ }^{1}$ and Horacio Schneider ${ }^{1}$ \\ ${ }^{\dagger}$ In memoriam. \\ ${ }^{1}$ Universidade Federal do Pará, Campus Universitário de Bragança
}

\begin{abstract}
Previous cytochrome B (CytB) mtDNA studies have suggested four species for the opossum genus Philander (four-eyed opossums), three (P. mcilhennyi, $P$. andersoni and $P$. opossum) from the Amazon and one ( $P$. frenata) from the Brazilian Atlantic forest. During a faunal survey nine specimens of Philander sp. and four of Didelphis marsupialis were collected in the Mamirauá Sustainable Reserve, Amazonas State, Brazil. Preliminary analyses based on morphology and geographical distributions were not conclusive, suggesting that Philander specimens could belong to either $P$. andersoni or $P$. opossum. In order to elucidate the relationship of this taxon to the remaining Amazonian taxa, seven Philander and two Didelphis specimens animals were sequenced for the cytB mtDNA gene and compared to other previously studied taxa. The maximum likelihood (ML), neighbor-Joining ( $N J)$ and maximum parsimony (MP) consensus bootstrap trees depicted six groups: Didelphis., P. frenata, $P$ andersoni, P. mcilhennyi, P.o. opossum and Philander sp. and Philander canus in a common assemblage supported by significant bootstrap values, suggesting that the Philander sp. from Mamiraua in fact belongs to the species Philander canus.
\end{abstract}

Key words: cytochrome B, Mamirauá, molecular phylogeny, mtDNA, Philander, pouched four-eyed opossum.

Received: February 4, 2005; Accepted: September 21, 2005.

According to Nowak (1999) the order Marsupialia presents 15 families, with the Didelphidae being the larger extant New World representative of this order. The Didelphidae encompasses 11 recent genera and 77 species, members of which occur from southeastern Canada through the eastern United States and Mexico and into South America to about 47 degrees South in Argentina. Kirsch (1977) proposed the recognition of two living subfamilies: Didelphinae (Marmosa, Monodelphis, Lestodelphis, Metachirus, Didelphis, Philander, Lutreolina, Chironectes) and Caluromyinae (Caluromys, Caluromysiops, and Glironia). Recently, nuclear gene sequence investigations by Jansa and Voss (2000) have found strong support for the monophyly of both the family Didelphidae (American opossums) and the subfamily Didelphinae. On the other hand, Gardner and Creighton (1989) suggested that the genus Marmosa is not monophyletic but is comprised of a series of separate taxa of unknown phylogenetic relationships, these authors creating the genus Gracilinanus to include some species while also suggesting that Marmosops, Micoureus, and Thylamys

Send correspondence to Claudia Nunes. Universidade Federal do Pará, Campus Universitário de Bragança, Alameda Leandro Ribeiro s/n, Bairro Aldeia, 68600-000 Bragança, PA, Brazil. Email: claudian@ufpa.br. should be raised to the status of genera. The lack of monophyly in the Marmosa has been corroborated by all recent molecular analyses (Jansa and Voss 2000; Kirsch and Palma 1995; Patton et al. 1996). In relation to the genus Philander (four-eyed opossums), Tiedemann 1808, which is widely distributed and euritopic in the tropical Amazon forest, the taxonomic status of many of species and subspecies is still highly controversial. According to Voss and Emmons (1996), congeneric species of Philander may be sympatric in several parts of the Amazon forest. Based on morphological data, Gardner (1993) recognized two Philander species, $P$. andersoni distributed from southern Venezuela to Peru and P. opossum occurring from Mexico to Paraguay and northeastern Argentina. Mitochondrial cytochrome B (CytB) data prompted Patton and Silva (1997) to propose four Philander species, three (P. mclihennyi, $P$. andersoni and $P$. opossum) from the Amazon region and one ( $P$. frenata) from the Brazilian Atlantic forest.

In the study described in this paper, we collected a sample of Philander specimens from the Mamirauá Sustainable Developmental Reserve, which is situated at the confluence of the Solimões and Japura rivers between $3^{\circ} 10^{\prime} \mathrm{S}$ and $64^{\circ} 41^{\prime} \mathrm{W}$ in the Brazilian state of Amazonas. Preliminary analyses based on morphology and geographical distributions were not conclusive, suggesting that the 
specimens could belong either to $P$. andersoni or P. opossum. Considering the large amount of data available on didelphid mitochondrial CytB, we decided to test whether or not this marker could be helpful in solving this question. During a faunal survey at the Mamirauá Reserve we used Tomahawk $(17$ x 17 x $61 \mathrm{~cm})$ traps to capture nine Philander (two of which were released) and four Didelphis specimens (Table 1) which were subsequently sacrificed. The specimens were measured and their skin and skulls prepared and deposited at the Mastozoology collection of the Emilio Goeldi Paraense Museum, Belém (PA), Brazil. Fresh tissues (blood or liver) were collected and preserved in $95 \%$ ethanol for the DNA procedures. Table 1 show details of all the opossum specimens used in this study.

The DNA was extracted according to Sambrook et al. (1989) and about 440 base pairs of the CytB region of the mitochondrial DNA (mtDNA) was sequenced for seven Philander and two Didelphis specimens using the MVZ05 (5'CGAAGCTTGATATGAAAAA CCATCGTTG3') and
MVZ14 (5'GGTCTTCATCTYHGGYTTACAAGAC3') primers (Smith and Patton, 1991). The polymerase chain reaction (PCR) was carried out in a final volume of $50 \mu \mathrm{L}$ containing $10 \mathrm{ng}$ of genomic DNA, $10 \mathrm{mM}$ Tris- $\mathrm{HCl}(\mathrm{pH}$ $8.85), 25 \mathrm{mM} \mathrm{KCl}, 5 \mathrm{mM}\left(\mathrm{NH}_{4}\right)_{2} \mathrm{SO}_{4}, 0.2 \mathrm{mM} \mathrm{dNTP}$, $50 \mathrm{pM}$ of each primer and 1 unit of Taq DNApolymerase (Qiagen, USA). Amplification was performed in a MJ Research thermocycler with a cycling profile of $94{ }^{\circ} \mathrm{C}$ for $3 \mathrm{~min}$ followed by 30 cycles of $94{ }^{\circ} \mathrm{C}$ for $1 \mathrm{~min}, 40{ }^{\circ} \mathrm{C}$ for $45 \mathrm{~s}, 72^{\circ} \mathrm{C}$ for $1 \mathrm{~min}$ and an additional extension period of $72{ }^{\circ} \mathrm{C}$ for $5 \mathrm{~min}$ in the last cycle. The PCR products were purified using ExoSAP-IT (USB, USA) and then sequenced using a dye-terminator cycle sequencing kit in a 377ABI automatic sequencer, according to protocols supplied by the manufacturers (Applied Biosystems, Foster, CA, USA).

The Philander and Didelphis Mamirauá specimens sequenced in the present work (deposited in GenBank under accession numbers DQ236271-DQ236279) together

Table 1 - Specimens and cytochrome B (CytB) sequences used in our study.

\begin{tabular}{|c|c|c|c|c|}
\hline Taxon $^{1}$ & $\operatorname{Code}^{2}$ & Origin & 0possum specimen register number ${ }^{3}$ & Sequence origin \\
\hline \multicolumn{5}{|l|}{ Didelphis species } \\
\hline D. albiventris & - & Venezuela & - & GenBank U34667 \\
\hline D. marsupialis & 1 & Rio Juruá, Amazonas (AM), Brazil & - & GenBank U34665 \\
\hline D. marsupialis & 2 & Mamirauá-AM, Brazil & MPEG24569 & Present work \\
\hline D. marsupialis & 3 & Mamirauá-AM, Brazil & MPEG24570 & Present work \\
\hline D. virginiana & - & - & - & GenBank $\underline{\text { Z29573 }}$ \\
\hline \multicolumn{5}{|l|}{ Philander species } \\
\hline Philander $s p$ & $1-7$ & Mamirauá-AM, Brazil & MPEG24571-24573, 26340, 26342, 26343, 26346 & Present work \\
\hline P. andersoni & 1 & Rio Jaú-AM, Brazil & YL1139 & $\mathrm{JP}^{4}$ \\
\hline P. andersoni & 2 & Parque yasuri, Equador & ROM104030 & JP \\
\hline P. andersoni & 3 & Peru & 6893 & JP \\
\hline P. andersoni & 4 & Peru & KU144120 & JP \\
\hline P. frenata & 1 & Espirito Santo, Brazil & MAM189 & JP \\
\hline P. frenata & 2 & Rio de Janeiro, Brazil & MNTJ-ORG1 & JP \\
\hline P. mcilhennyi & 1 & Rio Juruá, Acre state, Brazil & MNFS1103 & JP \\
\hline P. mcilhennyi & 2 & Rio Juruá-AM, Brazil & JLP15702 & JP \\
\hline P. mcilhennyi & 3 & Rio Juruá-AM, Brazil & MNFS383 & JP \\
\hline P. mcilhennyi & 4 & Rio Juruá-AM, Brazil & JLP16069 & JP \\
\hline P.mcilhennyi & 5 & Rio Urucu-AM, Brazil & MNFS146 & JP \\
\hline P. o canus & $1-2$ & Rio Juruá-AM, Brazil & JLP15395 & JP \\
\hline P. opossum opossum & 1 & Rio Negro-AM, Brazil & 16785 & JP \\
\hline P. о. opossum & 2 & Guiana & 31732 & JP \\
\hline P. о. opossum & 3 & Guiana & 31047 & JP \\
\hline P. о. opossum & 4 & Rio Xingu, Pará, Brazil & 542907 & JP \\
\hline P. o. fuscogriseus & - & Boca del Toro, Panama & USNM464248 & JP \\
\hline
\end{tabular}

${ }^{1}$ Common names: $D$. albiventris $=$ White-eared opossum; $D$. marsupialis $=$ Southern opossum; $P$. andersoni $=$ Black four-eyed opossum; $P$. frenata $=\mathrm{A}$ four-eyed opossum; Philander mcilhennyi = Mcilhenny's four-eyed opossum; and P. o. canus, P. o. opossum, P. o. fuscogriseus and Philander sp. $=$ Gray four-eyed opossum; ${ }^{2}$ Code $=$ numbers used in Fig. $1 ;{ }^{3}$ Emilio Goeldi Paraense Museum, Belem, Brazil; ${ }^{4}$ CytB sequences provided by James Patton. 
with sequences from the Philander species $P$. opossum opossum, $P$. opossum fuscogrieseus, $P$. opossum canus, $P$. andersoni, $P$. mcilhennyi, $P$. frenata and the Didelphis species $D$. albiventris and D. virginiana (kindly provided by James Patton) and the Didelphis virginiana GenBank Z29573) were automatically aligned using the Clustal W program (Thompson et al., 1994) and subsequently slightly modified using the BIOEDIT sequence editor (Hall, 1999).

A divergence matrix was constructed using evolutionary model parameters selected by the Modeltest program version 3.06 (Posada and Crandall, 1998) and phylogenetic analysis was carried out using maximum parsimony (MP) and neighbor joining (NJ) analysis and the PAUP* program version 4b10 (Swofford, 2003). The Treefinder program (Jobb et al., 2004) was used in the maximum likelihood (ML) analyses including bootstraps. Tree topology confidence was assessed by bootstrapping 1000 pseudo-replicates for the MP and NJ analyses and 500 pseudo-replicates for ML analyses.

The CytB sequences were tested for saturation by plotting TN93 distances against transition and transversion values using the DAMBE program (Xia and Xie, 2001) and no indication of saturation was observed even at the highest divergencies. The evolutionary model that best fitted the data set was TN93 (Tamura and Nei, 1993) with rates following a gamma distribution. The parameters of the evolutionary model chosen by the ModelTest used in the PAUP* program were as follows: Base $=0.3205,0.2335$ and $0.1409 ; \mathrm{Nst}=6$; Rmat $=1.0000,6.5252,1.0000,1.0000$ and 19.0258; Rates $=$ gamma; Shape $=0.2352$; and Pinvar $=0$. Distances were estimated using both the PAUP4b10 and MEGA 2.1 (Kumar et al., 2001) programs, which generate similar values except that Mega 2.1 has the option of comparing average genetic divergencies between groups (Table 2) as well as group standard errors.

We found that the TN93 genetic distances (d) varied from 0.04 to 0.36 , with our Philander sp. specimens from Mamirauá clearly being most closely related to $P$. canus $(\mathrm{d}=0.004 \pm 0.02)$ followed by P. mcilhennyi $(\mathrm{d}=0.047 \pm$ 0.02 ). The next grouping most strongly related to our $P$ hilander $s p$ specimens was that of $P$. andersoni and $P$. opossum whose distance from the Philander $s p(\mathrm{~d}=0.07$ to
0.08 ) were quite similar. Our data shows that $P$. frenata and Didelphis are undoubtedly the most divergent taxa, being this degree of divergence compatible to differences between distinct genera and similar results having been described previously (Patton and Silva, 1997).

Our MP analyses showed that among the 435 characters, 328 were constant, 24 were parsimony-uninformative and 83 parsimony-informative. The score of the best 7410 equally parsimonious trees was 187 and the consistency index was 0.615 . All methods used yielded the same tree topology. The consensus tree is presented in the Figure 1 with bootstrap values at the nodes (ML, NJ and MP). The topology clearly shows six groups: Didelphis $(\mathrm{ML}=92 \%, \mathrm{NJ}=$ $84 \%$ and $\mathrm{MP}=76 \%)] ;$. frenata $(\mathrm{ML}, \mathrm{NJ}$ and $\mathrm{MP}=100 \%$ ); P. a. andersoni (ML, NJ and MP 100\%); P. a. mcilhennyi $(\mathrm{ML}=99 \%, \mathrm{NJ}=99 \%, \mathrm{MP}=94 \%)$ and $P$. $o$. opossum ( $\mathrm{ML}=87 \%, \mathrm{NJ}=81 \%$ and $\mathrm{MP}=76 \%$ ), with $P h i$ lander sp. and Philander o. canus belonging to a common assemblage ( $\mathrm{ML}=98, \mathrm{NJ}=83$ and $\mathrm{MP}=92 \%)$.

Our ML, NJ and MP data suggests that the Philander $s p$. specimens from Mamirauá belong to the species Philander o. canus. However, the relationships of $P$. o. canus, $P$. andersoni and $P$. mclilhennyi, $P$. o. opossum, $P$. $o$. fuscogriseus, were not resolved. Indeed, the bootstrap values supporting $P$. o. canus, $P$. mcilhennyi and $P$. o. opossum $(\mathrm{ML}=64 \%, \mathrm{NJ}=63$ and $\mathrm{MP}=0 \%)$ also suggests an unsolved phylogenetic relationship, as previously observed by Patton and Costa (2003). Clearly, the hypothesis of $P$. frenata from the Brazilian Atlantic forest being a different taxonomic entity (Patton and Costa, 2003) was also confirmed by our work. Indeed, our genetic divergence estimates between $P$. frenata and other Philander species shown in Table 2 strongly suggest that they may belong to different genus instead of different species of the same genus. Our genetic divergence estimates using the evolutionary model that best fitted the data showed divergence values of $P$. frenata in relation to the other opossums of the same scale of those from Didelphis in relation to the other opossums. Considering our results, the mitochondrial cytochrome B sequences proved to be useful as a complementary tool for taxonomic inference. As pointed out by Patton and Costa (2003) the true diversity of rainforest mar-

Table 2 - Genetic distances estimated according to Tamura and Nei (1993) modeled by a gamma distribution with alpha parameter equal to 0.23 (lower diagonal). Standard errors estimated using bootstrap (upper diagonal).

\begin{tabular}{lccccccc}
\hline & Philander sp. & P. canus & P. andersoni & P. opossum & P. mcilhennyi & P. frenata & Didelphis \\
\hline Philander sp & & 0.002 & 0.031 & 0.026 & 0.018 & 0.126 & 0.120 \\
P. canus & 0.004 & & 0.029 & 0.025 & 0.017 & 0.133 & 0.114 \\
P. andersoni & 0.087 & 0.079 & & 0.027 & 0.032 & 0.281 & 0.217 \\
P. opossum & 0.072 & 0.065 & 0.088 & & 0.031 & 0.252 & 0.198 \\
P. mcilhennyi & 0.047 & 0.041 & 0.100 & 0.092 & & 0.143 & 0.184 \\
P. frenata & 0.242 & 0.246 & 0.345 & 0.343 & 0.270 & & 0.133 \\
Didelphis & 0.244 & 0.232 & 0.347 & 0.363 & 0.327 & 0.286 & \\
\hline
\end{tabular}




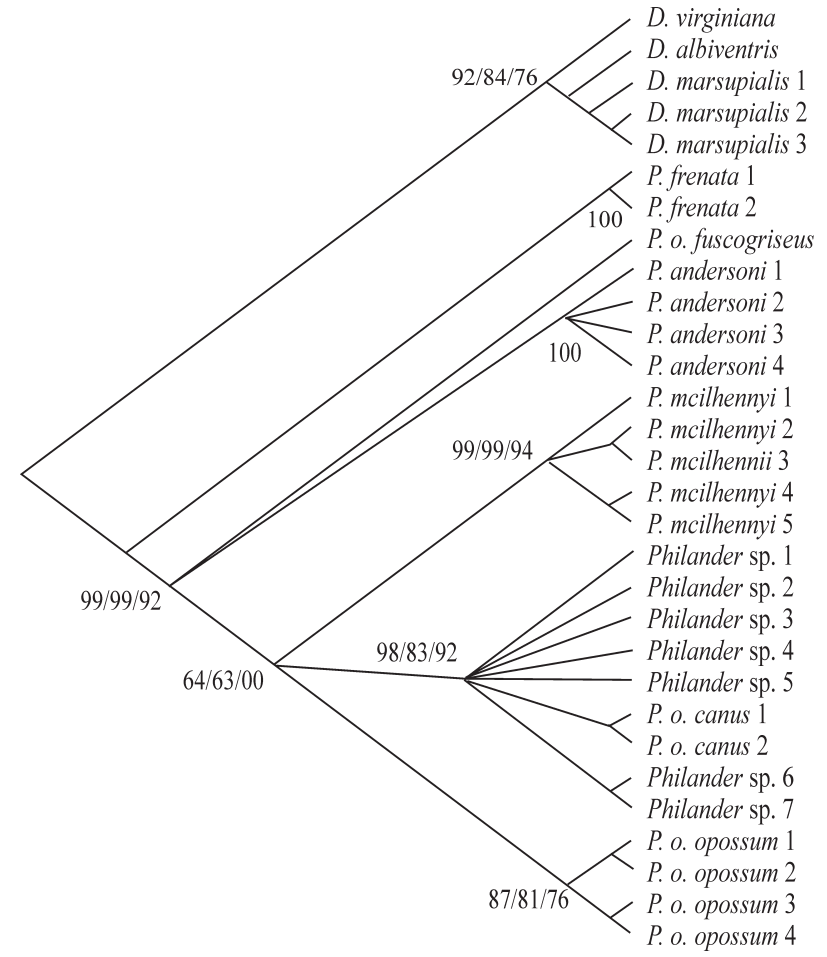

Figure 1 - Consensus tree of 433 base pairs of the mitochondrial Cytochrome $\mathrm{B}(\mathrm{CytB})$ gene with bootstrap values on the right corresponding to maximum likelihood (ML), Neighbor-Joining (NJ) and Maximum parsimony (MP) analyses, respectively.

supials will require a concentrated effort of multiple individuals working in collaboration, and we believe that the work reported in our present paper was an initial step in this direction.

\section{Acknowledgments}

The authors thank the following: Dr. James L. Patton (University of California at Berkeley) who kindly provided some of the sequences used in this work; Dr. Maria Nazaré Ferreira da Silva (responsible for the zoological collection of Instituto de Pesquisa da Amazonia - INPA) for fruitful discussions on the taxonomy of the Mamirauá specimens; and the anonymous reviewers for helpful comments. Special thanks go to the Mamirauá Sustainable Reserve. This work was supported by the Brazilian agencies CAPES, CNPq and UFPA.

\section{References}

Gardner AL (1993) Order Didelphimorphia, in Mammal species of the world: A taxonomic and geographic reference, 2 nd ed. Smithsonian Institution Press, Washington DC, pp 15-23.

Gardner AL and Creighton GK (1989) A new generic name for Tate's (1933) microtarsus group of South American mouse opossums (Marsupialia, Didelphidae). Proceedings of the Biological Society of Washington, 102:3-7.
Hall TA (1999) BioEdit: A User-Friendly Biological Sequence Alignment Editor and Analysis Program for Windows 95/98/NT. Nucleic Acids Symposium Series 41:95-98.

Jansa SA and Voss RS (2000) Phylogenetic studies on didelphid marsupials I Introduction and preliminary results from nuclear IRBP gene sequences. Journal of Mammalian Evolution 7:43-77.

Jobb GA, von Haeseler A and Strimmer K (2004) TREEFINDER: A powerful graphical analysis environment for molecular phylogenetics. BMC Evolutionary Biology 4:18. Kirsch JAW and Palma RE (1995) DNA-DNA hybridization studies of carnivorous marsupials V A further estimate of relationships among opossums (Marsupialia, Didelphidae). Mammalia 58:402-25.

Kirsch JA (1977) The comparative serology of Marsupialia, and a classification of marsupials. Austral J Zool, Suppl Ser 52:1152.

Kumar S, Tamura K, Jakobsen IB and Nei M (2001) MEGA2: Molecular Evolutionary Genetics Analysis Software. Arizona State University, Tempe, Arizona.

Nowak, RM (1991) Walker's Mammals of the World. 6th edition, v. II. The John Hopkins Univ. Press, Baltimore and London, pp 10-113.

Patton JL and da Silva MNF (1997) Definition of species of pouched four-eyed opossums (Didelphidae, Philander). Journal of Mammalogy 78:90-102

Patton JL, dos Reis SF and da Silva MNF (1996) Relationships among didelphid marsupials based on sequence variation in the mitochondrial cytochrome $b$ gene. Journal of Mammalian Evolution 3:3-29.

Patton JL and Costa LP (2003) Molecular phylogeography and species limits in rainforest didelphid marsupials of South America. In: Jones M, Dickman C and Archer M (eds) Predators with Pouches: The Biology of Carnivorous Marsupials. Sciro Publishing, Australia, pp 63-81.

Posada D and Crandall KA (1998) MODELTEST: Testing the model of DNA substitution. Bioinformatics 14:817-818.

Sambrook J, Fritsch E and Maniatis T (1989) Molecular Cloning: A Laboratory Manual. Cold Spring Harbor Laboratory Press, New York.

Smith MF and Patton JL (1991) Variation in mitochondrial cytochrome b sequence in natural populations of South American akodontine rodents (Muridae, Sigmodontinae). Mol Biol Evol 8:85-103.

Swofford DL (2003) PAUP* - Phylogenetic Analysis Using Parsimony (*and other Methods), Version 4.0b 10. Sinauer Associates, Sunderland, Massachusetts.

Tamura K and Nei M (1993) Estimation of the number of nucleotide substitutions in the control region of mitochondrial DNA in humans and chimpanzees. Molecular Biology and Evolution 10:512-526.

Thompson JD, Higgins DG and Gibson TJ (1994) CLUSTAL W: Improving the sensitivity of progressive multiple sequence alignment through sequence weighting, positions-specific gap penalties and weight matrix choice. Nucleic Acids Research 22:4673-4680.

Voss RS and Emmons LH (1996) Mammalian diversity if neotropical lowland rainforests: A preliminary assessment. Bulletin of the American Museum of Natural History 230:1-115.

Xia X and Xie Z (2001) DAMBE: Data analysis in molecular biology and evolution. Journal of Heredity 92:371-373. Associate Editor: Sérgio Furtado dos Reis 